\begin{tabular}{|c|l|}
\hline Title & Growth of porous anodic al umina films in hot phosphate-glycerol electrolyte \\
\hline Author(s) & Y ang, S.; A oki, Y.; Skeldon, P.; Thompson, G. E.; Habazaki, H. \\
\hline Citation & Journal of Solid State Electrochemistry, 15(4), 689-696 \\
\hline https://doi.org/10.1007/310008-010-1141-6 \\
\hline Issue Date & 2011-04 \\
\hline Doc URL & http://hdl.handle.net/2115/47408 \\
\hline Rights & The original publication is available at www.springerlink.com. \\
\hline Type & article (author version) \\
\hline File Information & JSSE15_689-696.pdf \\
\hline
\end{tabular}

Instructions for use 


\section{Growth of porous anodic alumina films in hot phosphate-glycerol electrolyte}

S. Yang ${ }^{1}$, Y. Aoki ${ }^{1}$, P. Skeldon ${ }^{2}$, G.E. Thompson ${ }^{2}$ and H. Habazaki ${ }^{1, *}$

${ }^{1}$ Division of Materials Chemistry, Faculty of Engineering, Hokkaido University, N13-W8,

Kita-ku, Sapporo 060-8628, Japan

${ }^{2}$ Corrosion and Protection Centre, School of Materials, The University of Manchester,

P.O.Box 88, Manchester M60 1QD, UK

*Corresponding author ; phone \& fax : +81-11-706-6575, e-mail:

habazaki@eng.hokudai.ac.jp 


\section{Abstract}

Growth of porous anodic alumina films has been examined at $10 \mathrm{~V}$ in hot phosphatecontaining glycerol electrolyte containing from 0.1 to 0.57 mass $\%$ water. The growth rate of the films is highly dependent upon the water content of the electrolyte, reducing markedly at a water content of 0.1 mass $\%$, an opposite trend to that found previously for formation of porous films on titanium and niobium. Chemical dissolution of the anodic alumina is also suppressed in electrolyte of low water content. GDOES depth profiles revealed that an increased water content of the electrolyte promoted incorporation of phosphorus species into the films, although chemical dissolution reduced the amounts of phosphorus in the outer regions. Carbon species also appeared to be present in films, particularly at lower water content. Using a niobium oxide outer layer to suppress chemical dissolution resulted in films that were about 1.2 times the thickness of the consumed aluminium for an electrolyte containing 0.25 mass $\%$ water. The expansion suggests possible contribution of field-assisted flow of film material in growth of the porous anodic film.

Keywords: porous anodic alumina, organic electrolyte, growth mechanism, TEM, GDOES 


\section{Introduction}

Porous anodic films formed in acid electrolytes have been used practically for the surface protection of aluminium alloys, for example, in architecture and aerospace. They have been of increased recent interest in the field of nanotechnology [1-5], since ideally ordered pores can now be developed [6]. The films comprise approximately hexagonal cells of amorphous alumina, each with a central pore, in a honeycomb-like arrangement $[7,8]$. A barrier layer of anodic alumina separates the aluminium substrate from the electrolyte. The thickness of the barrier layer and the size of the cells change linearly with the anodizing voltage, with proportionalities of $\sim 1$ and $2.8 \mathrm{~nm} \mathrm{~V}^{-1}$ respectively $[8,9]$. The porous layer thickens approximately in proportion to the anodizing charge, up to several tens of micrometres. The electric field is significant only in the barrier layer, inducing migration of $\mathrm{Al}^{3+}$ ions outward and $\mathrm{O}^{2-}$ ions inward. New film material is developed only at the metal/film interface by inward migration of $\mathrm{O}^{2-}$ ions inward, with outwardly mobile $\mathrm{Al}^{3+}$ ions being directly ejected to the electrolyte at the film/electrolyte interface [10]. 
The mechanism of film growth and pore generation remains a subject of interest, since the details of ionic migration and pore formation processes are still subjects of discussion. From sequential anodizing experiments using ${ }^{18} \mathrm{O}$ enriched and depleted $\mathrm{H}_{2} \mathrm{SO}_{4}$ electrolytes, pore formation by field-assisted dissolution has been proposed [11]. Recent studies using a nanometre-thick tungsten tracer layer incorporated into porous anodic films suggest that flow of alumina may also have a major role in film formation $[12,13]$. The flow of anodic oxide arises from field-assisted plasticity of the film and the generation of stress due to electrostriction and the formation of film material $[14,15]$. The displacement of film material from the pore base to the pore wall may explain the increased thickness of the alumina film with respect to the thickness of aluminium that is oxidized [16].

Porous anodic alumina films are usually formed in aqueous acid electrolytes, such as sulphuric acid, oxalic acid and phosphoric acid. Recently, it has been found that porous anodic oxide films are formed in phosphate-glycerol electrolyte at an elevated temperature of $433 \mathrm{~K}$. In this electrolyte, porous films may be developed on a range of valve metals, including aluminium [17], niobium [18], tantalum [17] and titanium [19-21]. In the present study, the growth of porous anodic alumina films has been investigated in $\mathrm{K}_{2} \mathrm{HPO}_{4}$-glycerol electrolyte at $433 \mathrm{~K}$ using field emission gun scanning electron microscopy (FEG-SEM), 
transmission electron microscopy (TEM) and glow discharge optical emission spectroscopy (GDOES). In particular, the influence of the water content of the electrolyte on the formation of the films has been examined, since its significant influence on the growth rate of porous titania and niobia films has recently been reported [20,22].

\section{Experimental details}

Specimens were prepared from $99.99 \%$ pure aluminium sheet that had been electropolished at $20 \mathrm{~V}$ in a mixture of ethanol and $60 \%$ perchloric acid (volume ratio of 20:80) below $283 \mathrm{~K}$ for $300 \mathrm{~s}$. In addition, aluminium films, with and without a very thin niobium outer layer, were deposited using magnetron sputtering. The substrates consisted either of glass or electropolished aluminium sheet that had been anodized to $200 \mathrm{~V}$ at $50 \mathrm{~A}$ $\mathrm{m}^{-2}$ in $0.1 \mathrm{~mol} \mathrm{dm}{ }^{-3}$ ammonium pentaborate electrolyte to provide a relatively flat surface. The use of sputtering-deposited aluminium films assisted investigations of influences of chemical dissolution in film formation. The sputter deposition was carried out using $99.999 \%$ pure aluminium and $99.9 \%$ pure niobium disk targets of $100 \mathrm{~mm}$ diameter in high purity argon gas of $0.3 \mathrm{~Pa}$ with a constant $\mathrm{DC}$ current of $0.5 \mathrm{~A}$. 
The various specimens were anodized at $10 \mathrm{~V}$ in stirred glycerol electrolyte containing $0.8 \mathrm{~mol} \mathrm{dm}^{-3} \mathrm{~K}_{2} \mathrm{HPO}_{4}$ at $433 \mathrm{~K}$ under a nitrogen atmosphere for $600 \mathrm{~s}$. The water content, measured by Karl Fischer titration using a Hiranuma Sangyo, AQV-7S instrument, in the electrolyte was $0.1,0.25$ or 0.57 mass $\%$. During anodizing, the water content in the electrolyte did not change largely. A constant current density of $250 \mathrm{~A} \mathrm{~m}^{-2}$ was applied before reaching the selected formation voltage. A platinum sheet was used as a counter electrode. In order to determine the thickness of the barrier layers of the porous films formed in the previous electrolyte, re-anodizing of specimens was carried out at a constant current density of $5 \mathrm{~A} \mathrm{~m}^{-2}$ in $0.1 \mathrm{~mol} \mathrm{dm}^{-3}$ ammonium pentaborate electrolyte.

The surfaces and cross-sections of the specimens, both before and after anodizing, were observed in a JEOL JSM-6500F field emission gun scanning electron microscope. Electron-transparent sections, $\sim 10 \mathrm{~nm}$ thick, of the sputter-deposited specimens before and after anodizing were prepared by ultramicrotomy. The sections were examined by in a JEOL, JEM-2000FX transmission electron microscope. Elemental depth profiles of the anodized specimens were obtained by GDOES, using a Jobin-Yvon 5000 RF instrument, in an argon atmosphere of $600 \mathrm{~Pa}$ with application of RF of $13.56 \mathrm{MHz}$ and power of $50 \mathrm{~W}$. Light emissions of characteristic wavelengths were monitored throughout the analysis with 
a sampling time of $0.01 \mathrm{~s}$ to obtain the depth profiles. The wavelengths of the spectral lines used were 396.152, 416.466, 178.287, 130.217 and $165.701 \mathrm{~nm}$ for aluminium, niobium, phosphorus, oxygen and carbon, respectively. The signals were detected from a circular area of approximately $4 \mathrm{~mm}$ diameter.

\section{Experimental Results}

\subsection{Influence of water content of the electrolyte}

Figure 1 shows the current transient of the electropolished aluminium during anodizing at $10 \mathrm{~V}$ in $0.8 \mathrm{~mol} \mathrm{dm}{ }^{-3} \mathrm{~K}_{2} \mathrm{HPO}_{4}$-glycerol electrolytes containing $0.1,0.25$ and 0.57 mass $\%$ water at $433 \mathrm{~K}$. Initially, the current decreased rapidly, showing a minimum at an anodizing time in the range $20-30 \mathrm{~s}$ for the electrolytes containing 0.25 and 0.57 mass $\%$ water. Subsequently, the current increased to 23 and $17 \mathrm{~A} \mathrm{~m}^{-2}$ within $80 \mathrm{~s}$, followed by a quasi-steady current of 21-22 and 16-17 $\mathrm{A} \mathrm{m}^{-2}$, in the electrolytes containing 0.25 and 0.57 mass $\%$ water respectively. In contrast, no obvious current increase was revealed in the electrolyte containing 0.1 mass $\%$ water, which resulted in a relatively low quasi-steady current density of $2.5 \mathrm{~A} \mathrm{~m}^{-2}$. The highest quasi-steady current density was obtained in the electrolyte containing 0.25 mass $\%$ water. 
In relation to the charges passed during anodizing for $600 \mathrm{~s}$ in the electrolytes containing different concentrations of water, the thicknesses of the anodic films are dependent upon the water content in the electrolytes. Transmission electron micrographs of ultramicrotomed sections for the anodized specimens (Fig. 2) disclose the development of a porous anodic oxide layer in the three electrolytes used. Only a thin layer of $\sim 50 \mathrm{~nm}$ thickness was generated in the electrolyte containing 0.1 mass $\%$ water, while the porous films formed in the electrolytes containing 0.25 and 0.57 mass $\%$ water are 400 and $300 \mathrm{~nm}$ thick respectively. From scrutiny of the micrographs, it is clear that the pore walls become thinner as the distance from the metal/film interface increases for the anodic films formed in the electrolytes containing 0.25 and 0.57 mass $\%$ water. The thinner pore walls in the outer regions of the anodic films are associated with chemical dissolution of the alumina during anodizing, as discussed later. However, the porosity of the anodic film formed in the electrolyte containing the lowest water content is apparently low, despite the similar anodizing times for all three specimens, suggesting reduced chemical dissolution in the electrolyte containing 0.1 mass $\%$ water. In addition, a bubble-like texture is displayed in the anodic film formed in this electrolyte. The texture appeared during electron-beam irradiation for TEM observation, suggesting that species incorporated into the film from the 
organic electrolyte, probably glycerol-derived species, may decompose under the electron beam. In all specimens, cellular metal surfaces are developed with the peak to peak distance being $35 \sim 40 \mathrm{~nm}$ in all specimens. Fine voids are also found at the metal/film interface for all three specimens. The formation of the voids on the high purity aluminium is the subject of a future study. The thicknesses of barrier layers, sandwiched by the porous layer and metal substrate, do not change significantly with the water content in electrolyte (Table 1). There is a good correlation between the film thickness and the electric charge passed during anodizing at $10 \mathrm{~V}$ in $0.8 \mathrm{~mol} \mathrm{dm}^{-3} \mathrm{~K}_{2} \mathrm{HPO}_{4}$-glycerol electrolytes with different water concentration (Fig. 3). The anodic film thickens in proportion to the electric charge, irrespective of the water content of the electrolytes. A slope of $3.5 \times 10^{-11} \mathrm{~m}^{3} \mathrm{C}^{-1}$ is calculated for the growth rate of the present porous anodic alumina films, which is about two third that for the growth of barrier-type anodic films at high current efficiency [23].

Compositional information for the anodic films has been obtained by GDOES elemental depth profiling analysis (Fig. 4). In Fig. 4, a sharp increase in aluminium intensity and rapid decrease in the oxygen intensity at sputtering times of 3.5, 13 and $10 \mathrm{~s}$ correspond to the metal/film interface for the anodic films formed in the electrolytes containing $0.1,0.25$ and 0.57 mass $\%$ water respectively. The ratio of the sputtering times for the latter two specimens is consistent with the thickness ratio of the anodic films (Table 1), but the sputtering time for the anodic film formed in the electrolyte containing 0.1 
mass $\%$ water is longer than that expected from the film thickness. The reduced average sputtering rate for the latter film is possibly due to its apparently low porosity (Fig. 2).

Phosphorus species are incorporated throughout the thickness of all three anodic films, but with a reduced content for the anodic film formed in the electrolyte containing 0.1 mass $\%$ water. The incorporation of phosphorus is significant in the inner regions of the other two anodic films, with its reduced presence in the outer part of the anodic films probably associated with chemical dissolution of the pore wall material. Phosphate ions are usually located in the outer part of the pore walls of porous anodic alumina films formed in aqueous phosphoric acid electrolytes [24]. The presence of carbon species is also evident throughout the film thickness in the anodic film formed in the electrolyte with the lowest water content, and in the outer part of the anodic film formed in the electrolyte containing 0.25 mass $\%$ water. The carbon concentration of the anodic film formed in the electrolyte with the highest water content is relatively low.

In order to examine the influence of water content on the field strength in the barrier layer of the anodic films, re-anodizing experiments have been carried out at a constant current density of $5 \mathrm{~A} \mathrm{~m}^{-2}$ in $0.1 \mathrm{~mol} \mathrm{dm}^{-3}$ ammonium pentaborate aqueous electrolyte. The voltage-time responses during re-anodizing (Fig. 5) reveal that the initial voltage surge is in the range of 13-15 V, suggesting similar thicknesses of the barrier layer in the anodic films formed in three different water contents of the electrolyte (Table 1).

\subsection{Thickness expansion by anodizing}


The ratio of the anodic film thickness to the thickness of aluminium consumed has been examined using sputter-deposited aluminium films anodized in the electrolyte containing 0.25 mass $\%$ water. The current transient of the aluminium film sputter-deposited on glass (Fig. 6) is similar to that of the electropolished aluminium sheet (Fig. 1). Following the quasi-steady current region up to an anodizing time of $530 \mathrm{~s}$, the current decreased rapidly, due to total consumption of the aluminium film. The complete anodizing of the aluminium film was confirmed from the transparency of the specimen. Figures $7 \mathrm{a}$ and $7 \mathrm{~b}$ reveal cross-sectional scanning electron micrographs before and after complete anodizing respectively. The aluminium film, of $420 \mathrm{~nm}$ thickness, is transformed into a porous anodic film of $440 \mathrm{~nm}$ thickness, with a pore size of $30 \mathrm{~nm}$ evident in Fig. 7c. Thus, the thickness of the anodic film exceeds that of aluminium consumed by a factor of only 1.05 .

In order to consider the influence of chemical dissolution during anodizing, an aluminium film with a thin niobium top layer was also anodized. Figure 8a discloses a transmission electron micrograph of the $364 \mathrm{~nm}$ thick aluminium film, attached to a barriertype amorphous anodic alumina layer, which appears at the bottom of the micrograph. A $\sim 6$ $\mathrm{nm}$-thick niobium layer is evident above the aluminium film. After complete anodizing, a porous $436 \mathrm{~nm}$ thick alumina film has developed, which is 1.2 times thicker than the consumed aluminium. Niobium oxide is present at the outer surface of the anodic film, as confirmed by GDOES elemental depth profile analysis (Fig. 9), although the amount of niobium is markedly reduced during anodizing. The increased expansion factor obtained 
with the use of a niobium layer has resulted from suppression of chemical dissolution of the anodic alumina by the outer layer of niobium oxide.

\section{Discussion}

\subsection{Influence of water content}

The importance of water content in the formation of porous anodic films on valve metals in hot phosphate-glycerol electrolytes has been reported previously [20, 22]. The growth rate of porous niobium oxide films at a formation voltage of $10 \mathrm{~V}$ is highly enhanced by the reducing water content to less than 0.1 mass $\%$ [22], which is associated with a reduced thickness of the barrier layer, and hence increased field strength in the barrier layer during film growth. The ionic migration is therefore enhanced, resulting in an increased growth rate of the anodic film. The incorporation of phosphate into the anodic film is also accelerated by a reduced water content, which may be due to the increase in the electric field [25]. Similarly enhanced film growth is also found in anodizing of titanium $[20]$.

In contrast to the anodizing behaviour of niobium and titanium, the growth rate of the porous anodic film is reduced markedly on aluminium in the electrolyte of the lowest water content, i.e. 0.1 mass $\%$. Further, the thickness of the barrier layer between the porous layer and aluminium substrate is not dependent strongly on the water content in the electrolyte. The thickness of the barrier layer is $14 \mathrm{~nm}$ at $10 \mathrm{~V}$ in the electrolyte containing 0.25 mass $\%$ water, corresponding to a field strength of $7.1 \mathrm{MV} \mathrm{cm}^{-1}$. This value is $\sim 30 \%$ lower than that in the barrier layer formed in acid aqueous electrolytes at room temperature 
$\left(\sim 10 \mathrm{MV} \mathrm{cm}^{-1}\right)$. The present films also undergo significant chemical dissolution in electrolytes containing 0.25 and 0.57 mass $\%$ water. The dissolution reduces the thickness of the pore walls especially in the outer regions of the films that are exposed for the longest time to the electrolyte (Figs. $2 \mathrm{~b}$ and 2c). The dissolution also results in thinning of the film, which is evident from the increased film thickness that results when the outer surface of the film is protected by a thin layer of niobium oxide. In contrast, relatively thick pore walls are displayed in the anodic film formed in the electrolyte containing only 0.1 mass $\%$ water (Fig. 2a).

It is well known that electrolyte anions species are generally incorporated into anodic alumina films formed in aqueous electrolytes [26, 27]. Phosphate anions are incorporated in the outer $\sim 70 \%$ of the film thickness for barrier-type anodic films formed at high current efficiency in phosphate-containing electrolyte [27]. In porous anodic films formed in phosphoric acid electrolyte, phosphate anions are incorporated in the outer part of pore walls as well as the outer part of the barrier layer [24]. In contrast, no detectable levels of phosphate incorporation have been reported in anodic alumina and tantala in hot phosphate-glycerol electrolyte [28]. The present GDOES elemental depth profiling revealed a limited level of phosphate incorporation for the film formed in an electrolyte with 0.1 mass $\%$ water, which increased when the water content was increased to 0.25 mass $\%$ or higher (Fig. 4). For the incorporation of phosphate into the anodic film, some amount of water in the glycerol electrolyte appears to be necessary. One of the possible reasons for the limited incorporation of phosphate when the water content is 0.1 mass $\%$, is the possibly competing incorporation of glycerol-derived species, as suggested by bubble-like feature 
found in Fig. 2a. In contrast with the behaviour of phosphorus species, the presence of carbon species appeared to be reduced with increasing content of water in the electrolyte. However, the reduced carbon content may be an effect of the degradation of the films, and further studies are required of the behaviour of the carbon species in the films.

\subsection{Mechanism of formation of porous oxide}

Currently, two mechanisms for formation of porous anodic films are possibly relevant: field-assisted dissolution and field-assisted plastic flow. In the first mechanism, a relatively constant thickness of the barrier layer during the formation of a porous film is achieved by a balance between the rate of formation of fresh film material, presumed to occur by inward migration of oxygen species to the metal/film interface, and an accelerated dissolution of the alumina at the pore base regions, due to the high electric field. In the second mechanism, flow of the anodic alumina away from the pore base regions replaces field-assisted dissolution as the main process that maintains a steady thickness of the barrier layer. The dominant mechanism appears to depend upon the electrolytes used [12, 29-32]. The plastic flow of film material in the barrier layer has been suggested when films are formed in phosphoric acid, sulphuric acid, malonic acid and oxalic acid [12, 13, 29, 31], which results in incorporation of anion species from the electrolyte, while field-assisted dissolution appear to be dominant in the formation of porous films in chromic acid and borax electrolytes, for which incorporation of electrolyte species into the film is negligible $[30,32,33]$. In the latter electrolytes, the thicknesses of the anodic films are similar to that of aluminium consumed by anodizing. In contrast, anodic films that are significantly 
thicker than the oxidized aluminium develop in the former electrolytes, which results mainly from the flow of the film material.

When barrier-type anodic alumina films, with relatively low amounts of incorporated electrolyte species, are formed at high current efficiency, the thickness of the anodic film is 1.61 times that of aluminium oxidized [34]. The inner $60 \%$ of the film material is developed at the metal/film interface by ingress of $\mathrm{O}^{2-}$ ions, with the remainder of the film generated at the film/electrolyte interface by egress of $\mathrm{Al}^{3+}$ ions (Fig. 10b). When porous alumina films are formed, the film material appears to be developed only at the metal/film interface and no film material is formed at the film/electrolyte interface, due to the direct ejection of $\mathrm{Al}^{3+}$ ions migrating to the interface [26]. The condition of ejection of all outwardly mobile $\mathrm{Al}^{3+}$ ions occurs at an efficiency of about $60 \%$, for anodizing at moderate current densities, when the volume of formed oxide is approximately equal to the volume of metal consumed (Fig. 10c). The formation of pores is usually associated with instability of the flat film surface when subjected to field-assisted dissolution of the alumina at local regions where the field was enhanced. Thus, if field-assisted dissolution is predominant in growth of a porous alumina film, the thickness of the anodic film should be similar to or less than that of aluminium oxidized (Fig. 10e).

The present study reveals that the thickness of the porous anodic film formed in the phosphate-glycerol electrolyte containing 0.25 mass $\%$ water at $433 \mathrm{~K}$ is 1.2 times that of aluminium oxidized. The value compares with a factor of about 1.35 reported for porous films formed at a constant current density of $50 \mathrm{~A} \mathrm{~m}^{-2}$ in $0.4 \mathrm{M}$ phosphoric acid electrolyte at $293 \mathrm{~K}$ [13]. However, the expansion of the film relative to the metal consumed tends to 
increase with increase of the current density. The low value of the expansion of the porous film formed in the glycerol-based electrolyte compared with a porous film formed at $50 \mathrm{~A}$ $\mathrm{m}^{-2}$ in phosphoric acid may be due to the influences of the relatively low current density of $\sim 20 \mathrm{~A} \mathrm{~m}^{-2}$ during anodizing in the region of quasi-steady current and the increased temperature of the electrolyte. For the present film formed in the glycerol electrolyte containing 0.25 mass $\%$ water, the expansion suggests possible contribution of field-assisted flow in growth of porous anodic films.

\section{Conclusions}

1) Porous anodic alumna films developed at $10 \mathrm{~V}$ in $0.1 \mathrm{~mol} \mathrm{dm}^{-3} \mathrm{~K}_{2} \mathrm{HPO}_{4}$-glycerol electrolytes containing $0.1-0.57$ mass $\%$ water at $433 \mathrm{~K}$, with the growth rate markedly reduced by a decrease in the water content to 0.1 mass $\%$.

2) Despite large dependence of the film growth rate on water content, the thickness of the barrier layer is almost independent of the water content in electrolyte.

3) Phosphorus and carbon species are incorporated into the films, with the amount of phosphorus species being enhanced in electrolyte of increased water content. However, the distributions of the incorporated species through the film thickness is affected by chemical dissolution of the film in the electrolyte, which occurs more rapidly in electrolytes of increased water content.

4) The thickness of the anodic film, protected by a niobium oxide top layer, which suppresses chemical dissolution of the alumina, is 1.2 times that of aluminium consumed following anodizing in an electrolyte containing 0.25 mass $\%$ water. 


\section{Acknowledgement}

The present work was supported by Global COE Program (Project No. B01: Catalysis as the Basis for Innovation in Materials Science) from the Ministry of Education, Culture, Sports, Science and Technology, Japan.

\section{References}

1. Masuda H, Satoh M (1996) Jpn J Appl Phys, Part 2-Let 35: L126-L129

2. Lakshmi BB, Patrissi CJ, Martin CR (1997) Chem Mater 9: 2544-2550

3. Nielsch K, Muller F, Li AP, Gosele U (2000) Adv Mater 12: 582-586

4. Sander MS, Prieto AL, Gronsky R, Sands T, Stacy AM (2002) Adv Mater 14: 665667

5. Ono S, Oide A, Asoh H (2007) Electrochim Acta 52: 2898-2904

6. Masuda H, Fukuda K (1995) Science 268: 1466-1468

7. Keller F, Hunter MS, Robinson DL (1953) J Electrochem Soc 100: 411

8. O'Sullivan JP, Wood GC (1970) Proc R Soc London, A 317: 511-543

9. Wood GC, O'Sullivan JP (1970) Electrochim Acta 15: 1865-1876 
10. Cherki C, Siejka J (1973) J Electrochem Soc 120: 784-791

11. Siejka J, Ortega C (1977) J Electrochem Soc 124: 883-891

12. Skeldon P, Thompson GE, Garcia-Vergara SJ, Iglesias-Rubianes L, Blanco-Pinzon CE (2006) Electrochem Solid State Let 9: B47-B51

13. Garcia-Vergara SJ, Skeldon P, Thompson GE, Habazaki H (2006) Electrochim Acta 52: $681-687$

14. Houser JE, Hebert KR (2009) Nat Mater 8: 415-420

15. Houser JE, Hebert KR (2008) Phys Status Solidi A 205: 2396-2399

16. Vrublevsky I, Parkoun V, Sokol V, Schreckenbach J, Marx G (2004) Appl Surf Sci 222: $215-225$

17. Lu Q, Alcala G, Skeldon P, Thompson GE, Graham MJ, Masheder D, Shimizu K, Habazaki H (2002) Electrochim Acta 48: 37-42

18. Lu Q, Hashimoto T, Skeldon P, Thompson GE, Habazaki H, Shimizu K (2005) Electrochem Solid State Let 8: B17-B20

19. Habazaki H, Oikawa Y, Fushimi K, Shimizu K, Nagata S, Skeldon P, Thompson GE (2007) Electrochim Acta 53: 1775-1781 
20. Habazaki H, Teraoka M, Aoki Y, Skeldon P, Thompsom GE (2010) Electrochim Acta 55: 3939-3943

21. Kim D, Lee K, Roy P, Birajdar BI, Spiecker E, Schmuki P (2009) Angew Chem Int Ed 48: 9326

22. Habazaki H, Oikawa Y, Fushimi K, Aoki Y, Shimizu K, Skeldon P, Thompson GE (2009) Electrochim Acta 54: 946-951

23. Harkness AC, Young L (1966) Can J Chem 44: 2409-2413

24. Thompson GE (1997) Thin Solid Films 297: 192-201

25. Schrijner AJ, Middelhoek A (1964) J Electrochem Soc 111: 1167-1169

26. Thompson GE, Xu Y, Skeldon P, Shimizu K, Han SH, Wood GC (1987) Phil Mag B 55: 651-667

27. Wood GC, Skeldon P, Thompson GE, Shimizu K (1996) J ElectrochemSoc 143: 7483

28. Lu Q, Skeldon P, Thompson GE, Habazaki H, Shimizu K (2005) Thin Solid Films 471: $118-122$

29. Garcia-Vergara SJ, Skeldon P, Thompson GE, Habakaki H (2007) Appl Surf Sci 254: $1534-1542$ 
30. Garcia-Vergara SJ, Skeldon P, Thompson GE, Habazaki H (2007) Surf Interface Anal 39: 860-864

31. Garcia-Vergara SJ, Skeldon P, Thompson GE, Habazaki H (2007) Corros Sci 49: $3772-3782$

32. Garcia-Vergara SJ, Skeldon P, Thompson GE, Habakaki H (2007) Corros Sci 49: 3696-3704

33. Garcia-Vergara SJ, Skeldon P, Thompson GE, Habazaki H (2007) Thin Solid Films 515: $5418-5423$

34. Pringle JPS (1980) Electrochim Acta 25: 1423-1437 
Figure captions

Fig. 1 Current-time responses of electropolished aluminium during anodizing at $10 \mathrm{~V}$ in 0.8 mol dm${ }^{-3} \mathrm{~K}_{2} \mathrm{HPO}_{4}$-glycerol electrolytes containing $0.1,0.25$, and 0.57 mass\% water at 433 K.

Fig. 2. Transmission electron micrographs of ultramicrotomed sections of aluminum anodized at $10 \mathrm{~V}$ in $0.8 \mathrm{~mol} \mathrm{dm}^{-3} \mathrm{~K}_{2} \mathrm{HPO}_{4}$-glycerol electrolytes containing $0.1,0.25$, and 0.57 mass $\%$ water at $433 \mathrm{~K}$ for $600 \mathrm{~s}$.

Fig. 3 Correlation between the thickness of the anodic oxide films and the electric charge passed during anodizing at $10 \mathrm{~V}$ in $0.8 \mathrm{~mol} \mathrm{dm}^{-3} \mathrm{~K}_{2} \mathrm{HPO}_{4}$-glycerol electrolytes with 0.1 , 0.25 and 0.57 mass $\%$ water at $433 \mathrm{~K}$ for $600 \mathrm{~s}$.

Fig. 4 GDOES elemental depth profiles of the aluminium specimens anodized at $10 \mathrm{~V}$ in $0.8 \mathrm{~mol} \mathrm{dm}^{-3} \mathrm{~K}_{2} \mathrm{HPO}_{4}$-glecerol electrolytes containing (a) 0.1 , (b) 0.25 and (c) 0.57 mass $\%$ water at $433 \mathrm{~K}$ for $600 \mathrm{~s}$.

Fig. 5 Voltage-time responses during re-anodizing of the aluminium specimens, which were anodized at $10 \mathrm{~V}$ in $0.8 \mathrm{~mol} \mathrm{dm}^{-3} \mathrm{~K}_{2} \mathrm{HPO}_{4}$-glycerol with different water contents at $433 \mathrm{~K}$, at $5 \mathrm{~A} \mathrm{~m}^{-2}$ in $0.1 \mathrm{~mol} \mathrm{dm}^{-3}$ ammonium pentaborate electrolytes at $293 \mathrm{~K}$.

Fig. 6 Current-time response of the sputter-deposited aluminium during anodizing at $10 \mathrm{~V}$ in $0.8 \mathrm{~mol} \mathrm{dm}^{-3} \mathrm{~K}_{2} \mathrm{HPO}_{4}$-glycerol electrolyte containing 0.25 mass\% water at $433 \mathrm{~K}$. 
Fig. 7 Scanning electron micrographs of the sputter deposited aluminum specimens (a) asdeposited and (b, c) after anodizing at $10 \mathrm{~V}$ in $0.8 \mathrm{~mol} \mathrm{dm}^{-3} \mathrm{~K}_{2} \mathrm{HPO}_{4}$-glycerol electrolyte containing 0.25 mass $\%$ water at $433 \mathrm{~K}$. (a, b) cross-section and (c) plan views.

Fig. 8 Transmission electron micrographs of ultramicrotomed sections of the sputter deposited aluminium with a thin niobium top layer (a) before and (b) after complete anodizing at $10 \mathrm{~V}$ in $0.8 \mathrm{~mol} \mathrm{dm}^{-3} \mathrm{~K}_{2} \mathrm{HPO}_{4}$-glycerol electrolytes containing 0.25 mass\% water at $433 \mathrm{~K}$.

Fig. 9 GDOES elemental depth profiles of sputter deposited aluminum specimens anodized aluminum at $10 \mathrm{~V}$ in $0.8 \mathrm{~mol} \mathrm{dm}^{-3} \mathrm{~K}_{2} \mathrm{HPO}_{4}$-glycerol electrolytes with 0.25 mass $\%$ water at 433 K. (a) before anodizing; (b) after partly anodizing; (c) after completely anodizing.

Fig. 10 Schematic illustration showing anodic film growth; (a) before anodizing, (b) barrier film growth at $100 \%$ efficiency, (c) barrier film growth at $60 \%$ efficiency with direct ejection of outwardly migrating $\mathrm{Al}^{3+}$ ions at the film/electrolyte interface, (d) porous film growth by field-assisted plastic flow and (e) porous film growth by field-assisted dissolution. 


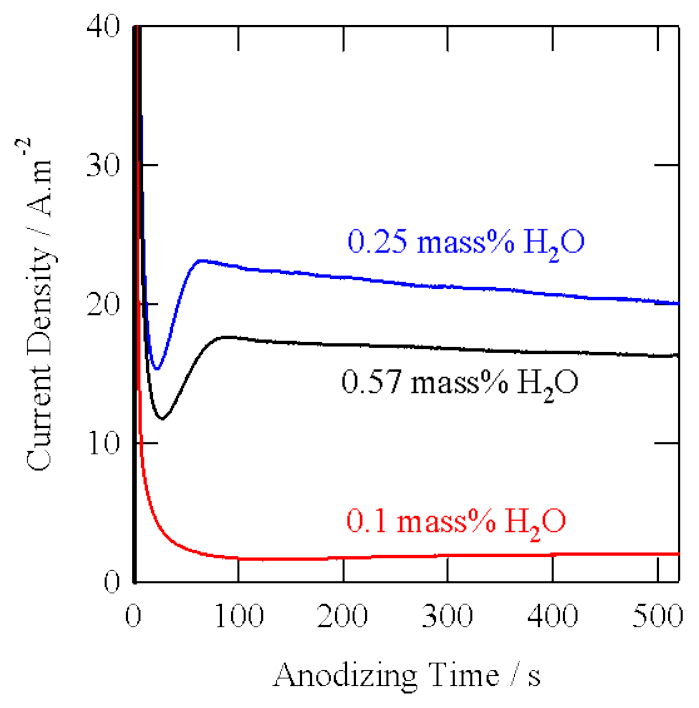

Fig. 1 Current-time responses of the electropolished aluminium during anodizing at $10 \mathrm{~V}$ in $0.8 \mathrm{~mol}$ $\mathrm{dm}^{-3} \mathrm{~K}_{2} \mathrm{HPO}_{4}$-glycerol electrolytes containing $0.1,0.25$, and 0.57 mass\% water at $433 \mathrm{~K}$. 

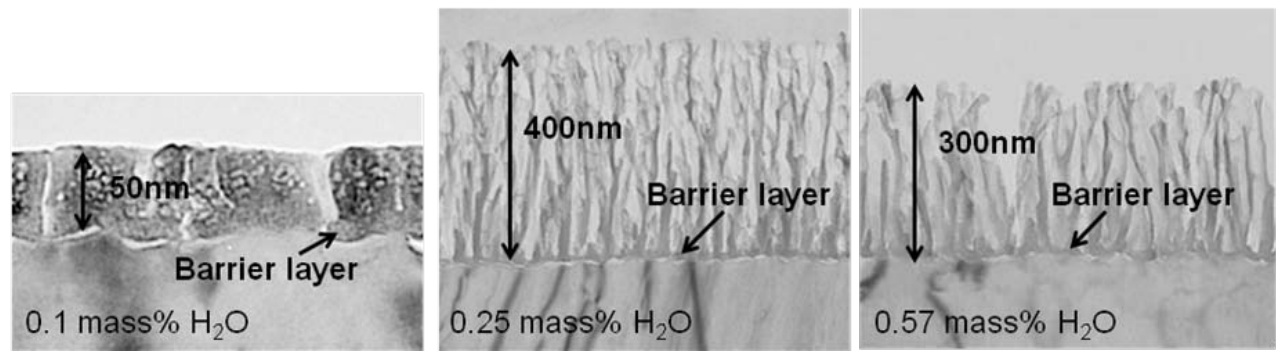

Fig. 2. Transmission electron micrographs of ultramicrotomed sections of aluminum anodized at $10 \mathrm{~V}$ in $0.8 \mathrm{~mol} \mathrm{dm}^{-3} \mathrm{~K}_{2} \mathrm{HPO}_{4}$-glycerol electrolytes containing $0.1,0.25$, and 0.57 mass\% water at $433 \mathrm{~K}$ for 600 s. 


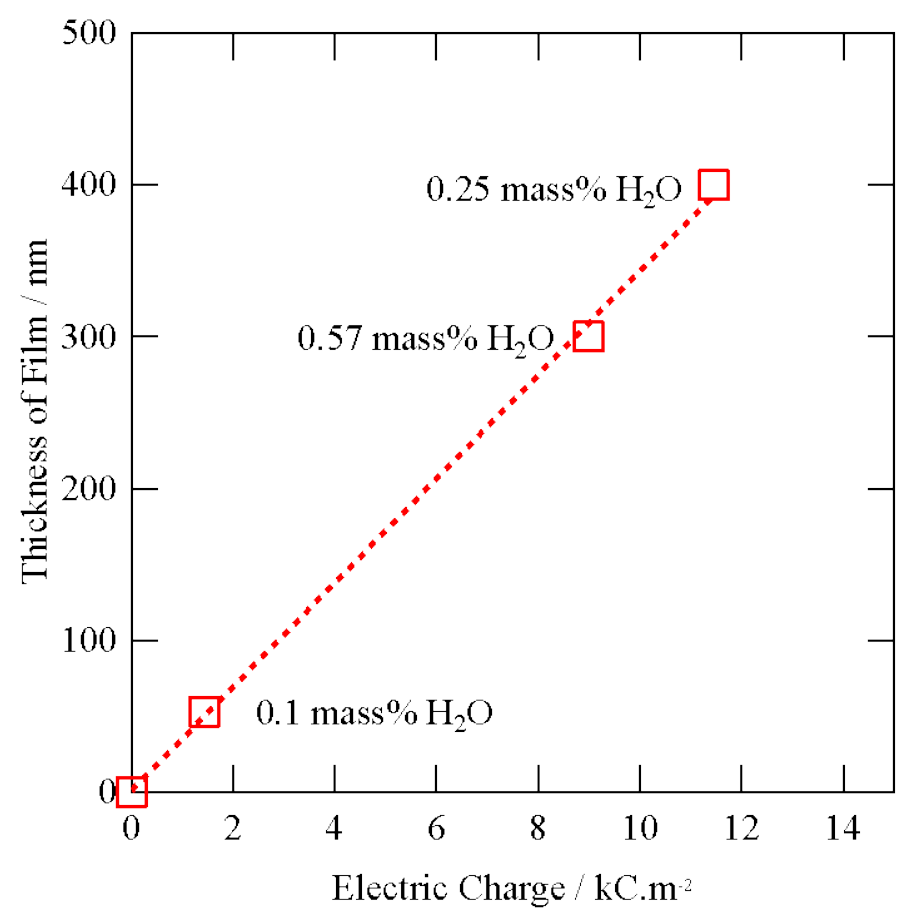

Fig. 3 Correlation between the thickness of the anodic oxide films and the electric charge passed during anodizing at $10 \mathrm{~V}$ in $0.8 \mathrm{~mol} \mathrm{dm}^{-3} \mathrm{~K}_{2} \mathrm{HPO}_{4}$-glycerol electrolytes with $0.1,0.25$ and 0.57 mass\% water at $433 \mathrm{~K}$ for $600 \mathrm{~s}$. 

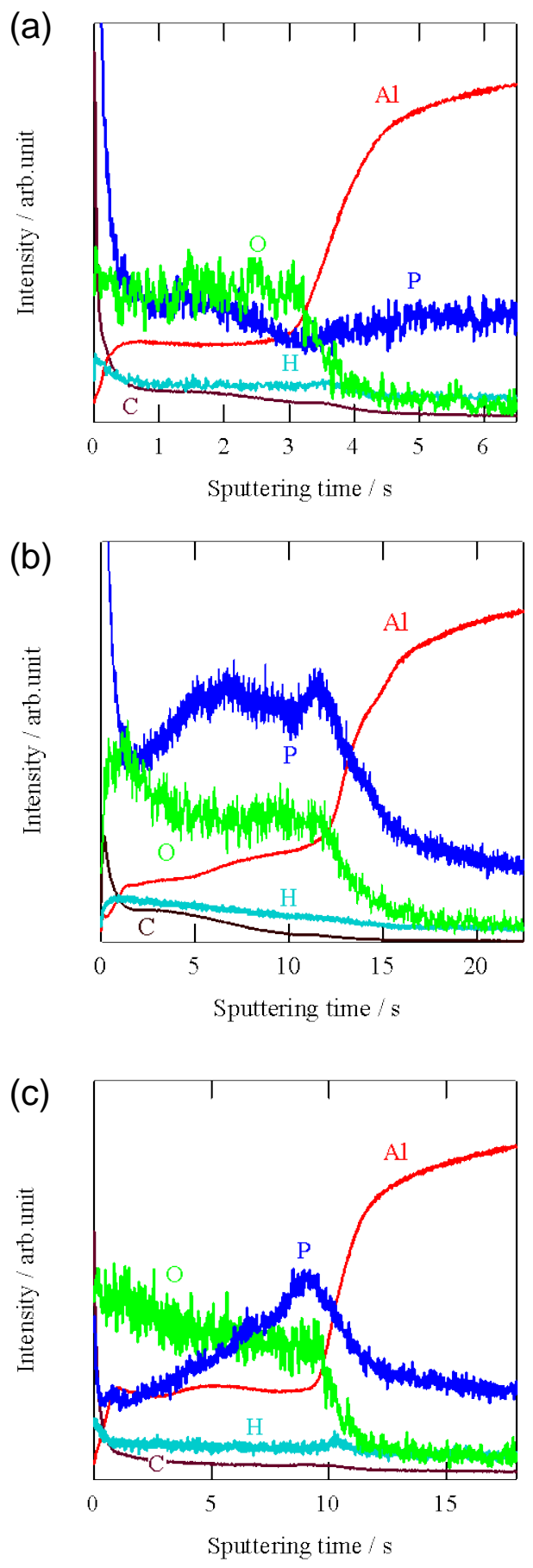

Fig. 4 GDOES elemental depth profiles of the aluminium specimens anodized at $10 \mathrm{~V}$ in $0.8 \mathrm{~mol} \mathrm{dm}^{-3}$ $\mathrm{K}_{2} \mathrm{HPO}_{4}$-glecerol electrolytes containing (a) 0.1 , (b) 0.25 and (c) 0.57 mass $\%$ water at $433 \mathrm{~K}$ for $600 \mathrm{~s}$. 


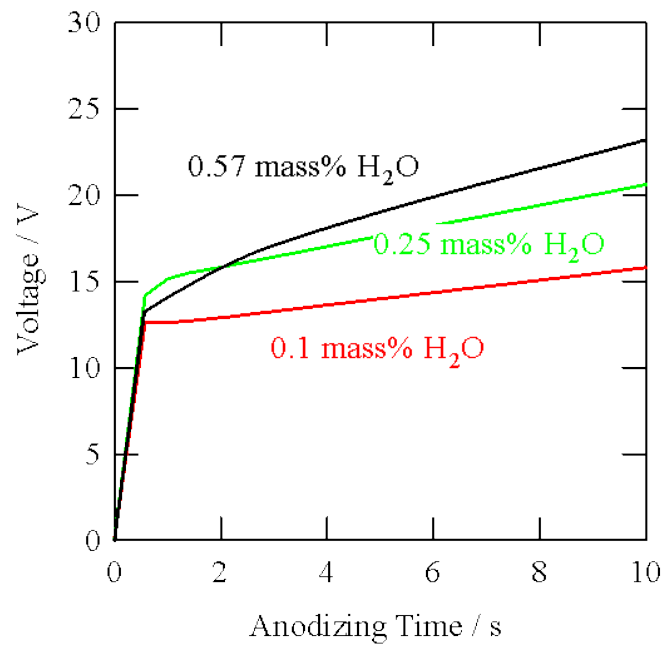

Fig. 5 Voltage-time responses during re-anodizing of the aluminium specimens, which were anodized at $10 \mathrm{~V}$ in $0.8 \mathrm{~mol} \mathrm{dm}^{-3} \mathrm{~K}_{2} \mathrm{HPO}_{4}$-glycerol with different water contents at $433 \mathrm{~K}$, at $5 \mathrm{~A} \mathrm{~m}^{-2}$ in $0.1 \mathrm{~mol} \mathrm{dm}^{-3}$ ammonium pentaborate electrolytes at $293 \mathrm{~K}$. 


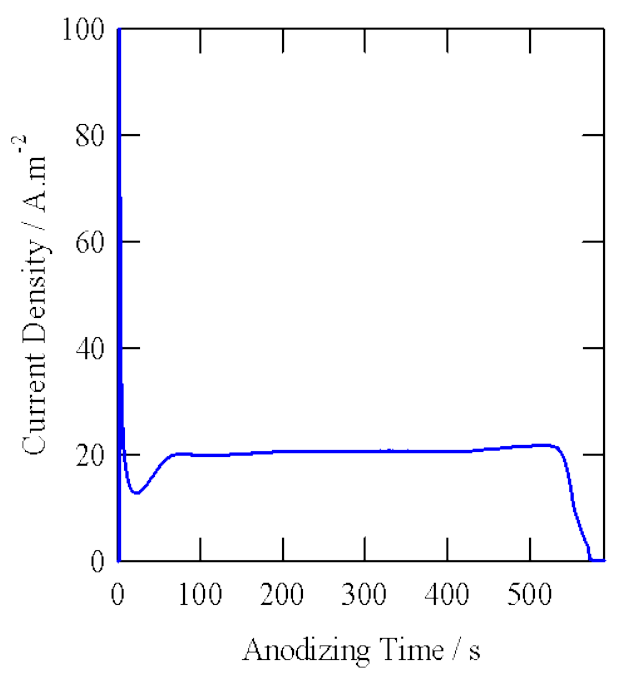

Fig. 6 Current-time response of the sputter-deposited aluminium during anodizing at $10 \mathrm{~V}$ in $0.8 \mathrm{~mol}$ $\mathrm{dm}^{-3} \mathrm{~K}_{2} \mathrm{HPO}_{4}$-glycerol electrolyte containing 0.25 mass\% water at $433 \mathrm{~K}$. 
(a)

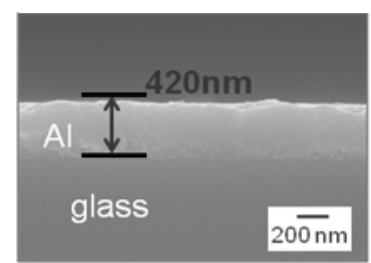

(b)

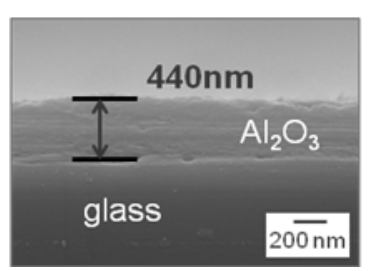

(c)

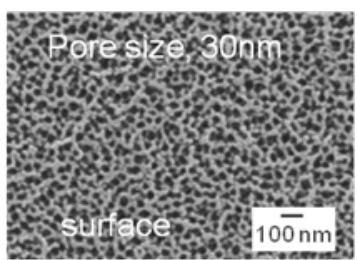

Fig. 7 Scanning electron micrographs of the sputter deposited aluminum specimens (a) as-deposited and (b, c) after anodizing at $10 \mathrm{~V}$ in $0.8 \mathrm{~mol} \mathrm{dm}^{-3} \mathrm{~K}_{2} \mathrm{HPO}_{4}$-glycerol electrolyte containing 0.25 mass\% water at $433 \mathrm{~K}$. (a, b) cross-section and (c) surface images. 
(a)

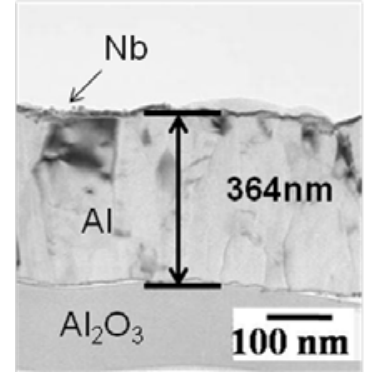

(b)

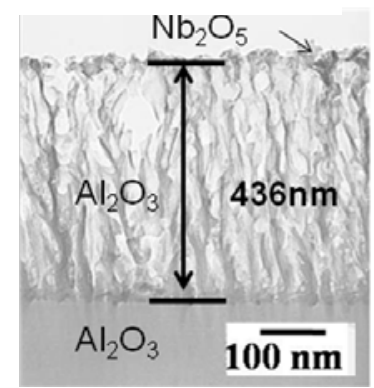

Fig. 8 Transmission electron micrographs of ultramicrotomed sections of the sputter deposited aluminium with a thin niobium top layer (a) before and (b) after complete anodizing at $10 \mathrm{~V}$ in 0.8 mol $\mathrm{dm}^{-3} \mathrm{~K}_{2} \mathrm{HPO}_{4}$-glycerol electrolytes containing 0.25 mass\% water at $433 \mathrm{~K}$. 
(a)
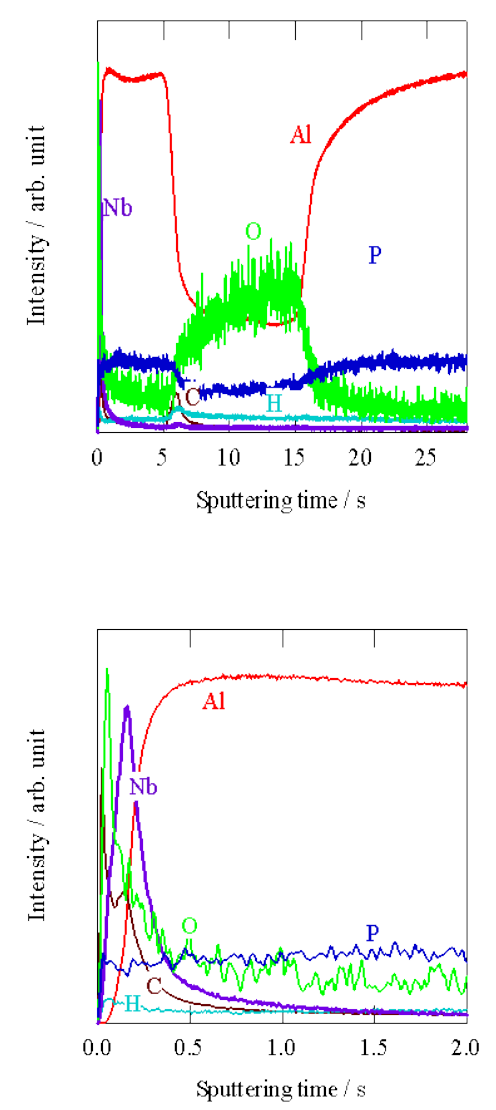

(b)
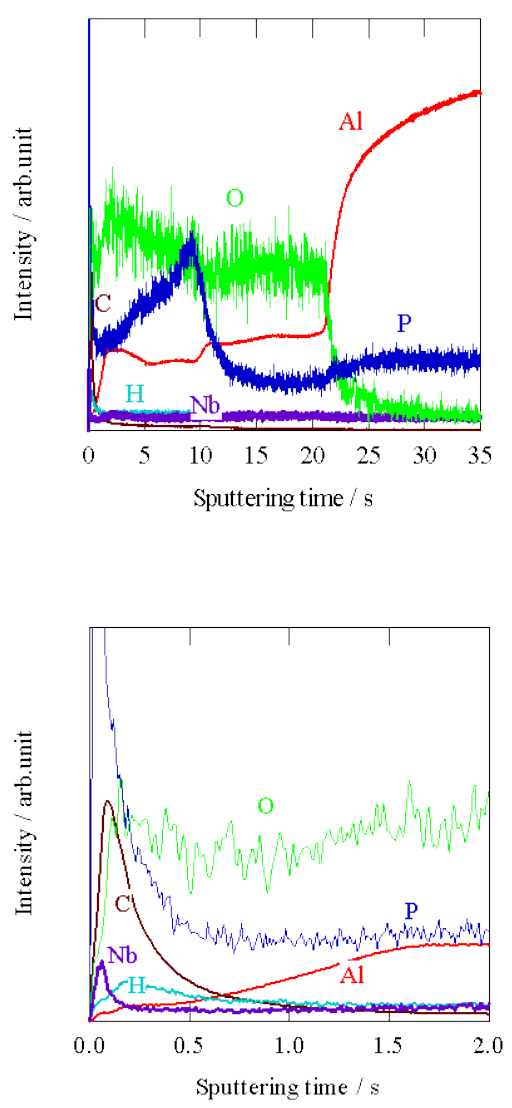

Fig. 9 GDOES elemental depth profiles of sputter deposited aluminum specimens anodized aluminum at $10 \mathrm{~V}$ in $0.8 \mathrm{~mol} \mathrm{dm}^{-3} \mathrm{~K}_{2} \mathrm{HPO}_{4}$-glycerol electrolytes with 0.25 mass\% water at $433 \mathrm{~K}$. (a) before anodizing; (b) after completely anodizing. 
(a)

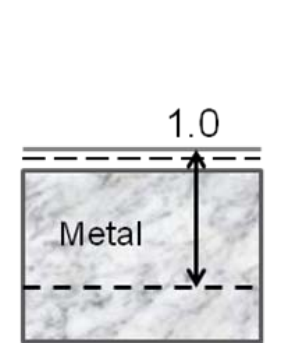

(b)

(c)

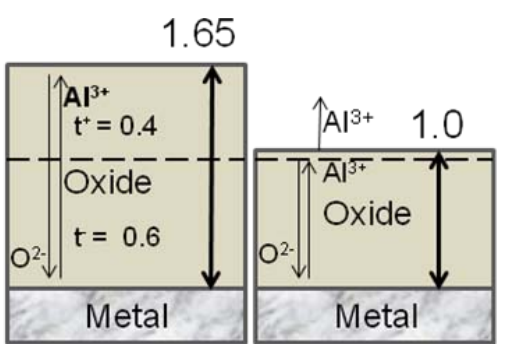

(d)

(e)

Fig. 10 Schematic illustration showing anodic film growth; (a) before anodizing, (b) barrier film growth at $100 \%$ efficiency, (c) barrier film growth at $60 \%$ efficiency with direct ejection of outwardly migrating $\mathrm{Al}^{3+}$ ions at the film/electrolyte interface, (d) porous film growth by field-assisted plastic flow and (e) porous film growth by field-assisted dissolution. 